\title{
Efficacy and Feasibility of the "Girls' Recreational Activity Support Program Using Information Technology”: A Pilot Randomised Controlled Trial
}

\author{
Tracey L. Kelty, Philip J. Morgan, David R. Lubans \\ Faculty of Education and Arts, School of Education, University of Newcastle, Newcastle, Australia \\ Email: Tracey.Kelty@newcastle.edu.au \\ Received October 27 ${ }^{\text {th }}$, 2011; revised November $30^{\text {th }}$, 2011; accepted December $10^{\text {th }}, 2011$
}

\begin{abstract}
This study evaluated the effects of the Girls Recreational Activity Support Program Using Information Technology (GRASP-IT) intervention. This group randomized controlled trial for older adolescent girls (15 years+) combined face-to-face sessions with the use of a social network website, Facebook. Baseline and follow-up measurements were taken for physical activity (5 day pedometer), height, weight, estimated $\mathrm{VO}_{2}$ max (Queen's College Step Test), self-efficacy and peer social support. A process evaluation was conducted and included questionnaires and focus groups interviews. Although, the intervention group increased physical activity (mean 1878 steps/day) the difference between groups was not significant ( $p=$ $0.11, d=0.8$ ). BMI, fitness, self-efficacy and peer support all improved for the intervention group, however, changes were not statistically significant between groups. Although participants enjoyed the face-toface component, engagement with the on-line component was low. Future interventions that utilize Facebook as a medium for increasing physical activity for adolescent girls require additional strategies to improve engagement and compliance.
\end{abstract}

Keywords: Physical Activity; Adolescent Girls; Intervention; Internet

\section{Introduction}

It is well established that physical activity is positively associated with improved health and wellbeing (Department of Health and Ageing, 2004; US Department of Health and Human Services, 2000; WHO, 2004) and can prevent future lifestyle diseases such as coronary heart disease, type 2 diabetes and obesity (Biddle, Gorley, \& Stensel, 2004; Booth et al., 2006; Nader, Bradley, Houts, Richie, \& O’Brien, 2008). Research has highlighted the steady decline in physical activity levels from childhood to adolescence, which is more pronounced among girls (Jamner, Spruijt-Metz, Bassin, \& Cooper, 2004; Nader et al., 2008; Pate, Dowda, O’Neill, \& Ward, 2007) The majority of Australian girls in the 14 - 16 year age group are not meeting the recommended physical activity guidelines (Department of Health and Ageing, 2008). In a recent study it was noted that only 33 per cent of girls met the national recommendations for moderate to vigorous physical activity (MVPA) on most days (i.e. at least 60 minutes of MVPA per day) and similarly, only $16 \%$ to $26 \%$ of girls aged 14 - 16 years met the recommended number of steps per day (i.e. between 11,000 and 12,000 steps) (Department of Health and Ageing, 2008; President's Council on Physical Fitness and Sports, 2002; Tudor-Locke \& Bassett Jr., 2004).

Strategies to reduce the decline in activity among adolescent girls and increase self-efficacy and motivation for an active lifestyle are clearly warranted (Lubans, Foster, \& Biddle, 2008; van Sluijs, McMinn, \& Griffin, 2007). Older adolescent girls are particularly challenging to motivate and engage in physical activity (Biddle \& Wang, 2003) and the school is one setting that has had varied success in increasing girls' physical activity
(Dishman et al., 2004; Eliakim et al., 1996; Jamner et al., 2004; Schneider et al., 2007; Stevens et al., 2005; van Sluijs et al., 2007). It is important to note that the school setting plays a role in the reduction of physical activity for older adolescent girls as the transition from junior secondary school to senior secondary school reduces the opportunities for many girls to be active at school. Senior secondary students (Grades 11 - 12) in New South Wales, Australia, currently move from compulsory physical education lessons and sport in Grades 7 - 10, to optional physical education and sport opportunities (New South Wales Government, 2010). Therefore, without continued support to be active a reduction in physical activity for this cohort is highly likely. Innovative strategies designed to combat the decline in physical activity observed during adolescence are needed and the internet has emerged as a promising strategy for promoting physical activity in youth populations (Norman et al., 2007). Notably, the use of social network sites in the world is increaseing with the most popular sites being Facebook and MySpace (ACM SIGCOMM Conference, 2008; Kazeniac, 2010; Thelwall, 2008), and these may be particularly appealing for adolescent girls. Given their popularity, online communication sites that utilize social networking are a potential tool that could allow adolescent girls to engage with each other to provide support to be active. However, few interventions have targeted older adolescent girls using the internet as a source of social support to be active (Norman et al., 2007). Furthermore, to the authors' knowledge, no previous study has used a social network site to promote physical activity in adolescent girls (van Sluijs et al., 2007). The aim of this paper is to report the feasibility and preliminary outcomes of the GRASP-IT pilot study. 


\section{Method}

\section{Recruitment and Description of Sample}

This study was a group randomized controlled trial (RCT) and involved two secondary schools. A convenience sample of five schools from New South Wales, Australia was approached to take part in the pilot study. Schools were approached based on similar drawing areas and the population of similar low/ medium socio-economic status. Two schools consented to participate and were randomly allocated to intervention or control. The study was open to all girls currently enrolled in Year 10 during 2009. Study participants were either intervention $(n=29)$ or control $(\mathrm{n}=23)$ and a mean age of $15.7 \pm 1.5$ years. The protocol for this study was reviewed and approved by The NSW State Education Research Approval Process (SERAP) and the University of Newcastle Human Research Ethics Committee (HREC) and each participant gave informed consent to participate in the study. Baseline and 12-week follow-up assessments were conducted (Tables 2 and 3 ).

The flow of participants through the study process is reported in Figure 1.

\section{Treatment Conditions}

The GRASP-IT intervention involved a 6-week school-based physical activity program delivered during school sport followed by a 6-week web-based program using Facebook outside of school hours. The online component was completed in the girls' own time as use of the social network site was not permitted during school hours. Girls at the control school continued their existing school sport program. The GRASP-IT intervention involved two distinct phases:

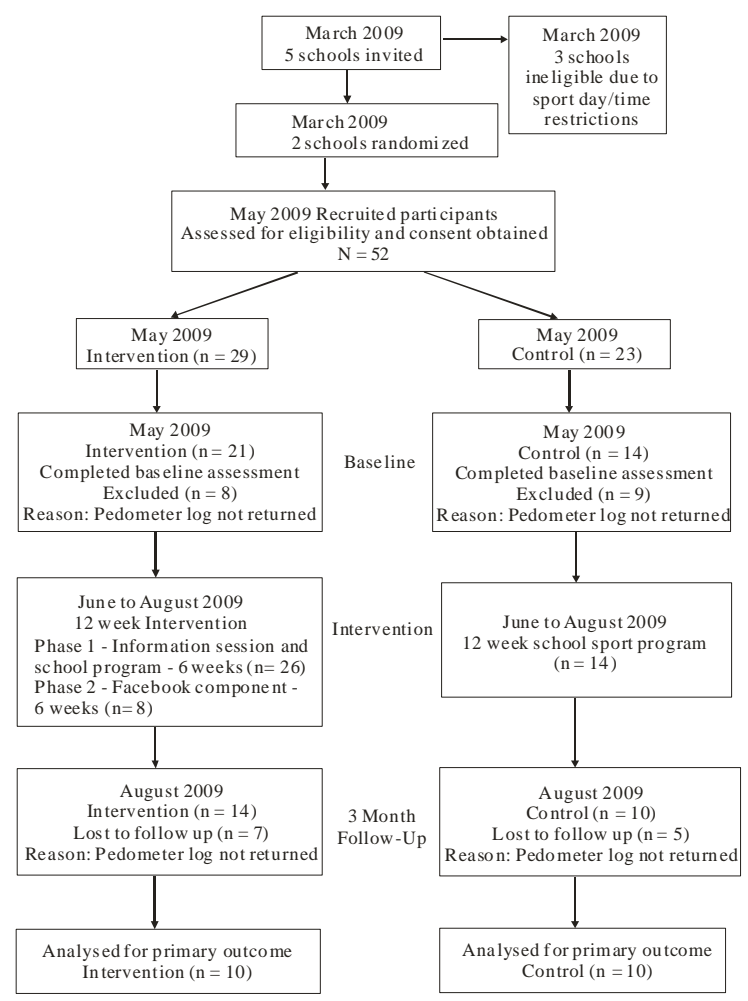

Figure 1.

Participant flow diagram analyzed for primary outcome.
Phase one was a face-to-face program that included a $30 \mathrm{~min}$ ute information session followed by approximately 60 minutes of physical activity for six weeks delivered by a member of the research team who is a qualified teacher. The intervention was developed in reference to Bandura's Social Cognitive Theory (Bandura, 1986) and was designed to target social support and self-efficacy as key mediators of physical activity behaviour change (Lubans, Foster, \& Biddle, 2008). The information sessions detailed strategies to be active alone and with friends as well as identification of exercise intensity necessary for improving fitness and strategies to increase physical activity (Department of Health and Ageing, 2008). The practical physical activity sessions were designed to enhance exercise self-efficacy and provided girls with an opportunity to participate in fun, easily accessible, recreational physical activity that utilized community and school facilities in a group setting. The sessions were designed to provide girls with activity of moderate-to-vigorous intensity that could easily be replicated by the girls in their spare time (Table 1).

Phase two was the online support component and targeted social support as an important mediator of behaviour change (Dishman et al., 2004). This part of the program consisted of information provision to increase physical activity and guidance for social support using the online communication medium Facebook. The girls from the intervention school were invited by the researcher, directly and via email, to join a closed group (to avoid contamination) on Facebook. The girls were asked to complete some simple physical activity tasks each week via online discussion. Due to the girls' low level of activity and motivation evident during the face-to-face sessions tasks set were created to motivate, engage and be achievable for all participants with opportunity to increase intensity if desired. The activities were set to be fun, of moderate intensity and the girls were encouraged to increase their physical activity a variety of innovative ways (Table 1).

The online task requests were placed on Facebook asking the girls to complete the weekly activities and then write on the "Wall" (a comment box) in the Facebook site to discuss their strategies to increase physical activity. The concluding investigation involved a process evaluation that used both questionnaires and focus groups to reveal insights into the recruitment, retention, adherence and satisfaction among the intervention group.

\section{Measures}

All assessments were conducted at the study schools using the same instruments and equipment at baseline and 12-week follow-up assessments. The primary outcome being physical activity was measured using pedometers. All participants wore a validated Yamax ${ }^{\odot}$ digi-walker SW-700 pedometer (Lubans, Morgan, \& Tudor-Locke, 2009; Schofield, Schofield, Hinckson, \& Mummer, 2007) for five days (four weekdays and one weekend day) and recorded their steps at night before sleep. The researcher provided the girls with a text message to place the pedometer on each morning and a message each night to record their daily steps in their log books. Secondary measures included BMI and cardio-respiratory fitness (CRF). Weight was assessed using calibrated digital scales (measuring kilograms) and height assessed using a calibrated stadiometer height sliding scale (measuring centimetres). These measurements enabled BMI scores to be calculated $\left(\mathrm{kg} / \mathrm{m}^{2}\right)$ and age specific cut-off points from the International Obesity Task Force were 
Table 1.

Intervention description and components.

\begin{tabular}{|c|c|c|c|}
\hline \multicolumn{4}{|c|}{ PHASE 1—Face to face component ( 6 weeks) } \\
\hline $\mathrm{Wk}$ & Specific focus for the information session & Activity (time/minutes) & Targeted construct \\
\hline 1 & $\begin{array}{l}\text { Introduction to GRASP-IT. } \\
\text { Target heart rate and use of pedometers for } \\
\text { fitness. }\end{array}$ & $\begin{array}{l}\text { Information and discussion (30 mins). } \\
\text { Beach walk (50 mins). }\end{array}$ & $\begin{array}{l}\text { Self-efficacy } \\
\text { Outcome expectancy }\end{array}$ \\
\hline 2 & $\begin{array}{l}\text { Goal setting to increase physical activity. } \\
\text { Use of music and pom-pom. }\end{array}$ & $\begin{array}{l}\text { Information and discussion ( } 30 \text { mins). } \\
\text { Pom-Pom aerobic class and floor work in recreation } \\
\text { room ( } 35 \text { mins). }\end{array}$ & $\begin{array}{l}\text { Behavioural strategies } \\
\text { Self-efficacy }\end{array}$ \\
\hline 3 & $\begin{array}{l}\text { Music speed/choice for an effective workout. } \\
\text { Counting beats in music for effective intensity } \\
\text { and duration. }\end{array}$ & $\begin{array}{l}\text { Information and discussion ( } 30 \text { mins). } \\
\text { Walk to local gym ( } 800 \mathrm{~m}) . \\
\text { Step class at local gym ( } 45 \text { mins). }\end{array}$ & Self-efficacy \\
\hline 4 & Alternative activities for health and fitness. & $\begin{array}{l}\text { Information and discussion ( } 30 \text { mins). } \\
\text { Walk to local gym ( } 800 \mathrm{~m}) . \\
\text { Pilates/fitness class ( } 50 \mathrm{mins})\end{array}$ & $\begin{array}{l}\text { Self-efficacy } \\
\text { Social support }\end{array}$ \\
\hline 5 & $\begin{array}{l}\text { Combining aerobic exercise with strength and } \\
\text { conditioning. }\end{array}$ & $\begin{array}{l}\text { Information and discussion ( } 30 \text { mins). } \\
\text { Walk to local gym }(800 \mathrm{~m}) \text {. } \\
\text { Aerobic class incorporating gymstick workout ( } 40 \\
\text { mins). }\end{array}$ & Self-efficacy \\
\hline 6 & $\begin{array}{l}\text { Guide to online use. } \\
\text { Importance of continuous and regular physi- } \\
\text { cal activity. }\end{array}$ & $\begin{array}{l}\text { Theory handout on Facebook registration. } \\
\text { Guide to joining Facebook and tips for use ( } 30 \text { mins). } \\
\text { Bush walk ( } 50 \text { mins). }\end{array}$ & $\begin{array}{l}\text { Self-efficacy } \\
\text { Social support } \\
\text { Outcome expectancy }\end{array}$ \\
\hline \multicolumn{4}{|c|}{ PHASE 2-Online component ( 6 weeks) } \\
\hline Wk & Specific focus for the week & Activity and information placed on Facebook & Targeted construct \\
\hline 7 & $\begin{array}{l}\text { Introduction to GRASP-IT online. } \\
\text { Goal setting update. } \\
\text { Tips for increasing physical activity. }\end{array}$ & $\begin{array}{l}\text { Instructed to suggest activities you can do with } \\
\text { friends to keep active-Encouraged to write on the } \\
\text { online Wall. } \\
\text { Discussion about how it feels during and after a } \\
\text { physical activity session l. } \\
\text { Provided links to websites for tips to be more active. }\end{array}$ & $\begin{array}{l}\text { Social support } \\
\text { Behavioural strategies } \\
\text { Self-efficacy } \\
\text { Outcome expectancy }\end{array}$ \\
\hline 8 & $\begin{array}{l}\text { Perception of current and future health status? } \\
\text { Nutrition and physical activity. }\end{array}$ & $\begin{array}{l}\text { Provided further links to follow and discover health } \\
\text { status and nutritional tips. } \\
\text { Promote discussion about nutrition and physical } \\
\text { activity. Challenge to eat foods that are not processed } \\
\text { for one day - Write on the wall. }\end{array}$ & $\begin{array}{l}\text { Social support } \\
\text { Self-efficacy } \\
\text { Outcome expectancy }\end{array}$ \\
\hline 9 & $\begin{array}{l}\text { Music as a motivator to be active. } \\
\text { Activities to do alone or with friends. }\end{array}$ & $\begin{array}{l}\text { Task set to choose songs of } 130 \text { - } 140 \text { beats per min- } \\
\text { ute to create a song list to use for stepping at home } \\
\text { and use a music device to step at your target heart } \\
\text { rate or walk to every day. }\end{array}$ & $\begin{array}{l}\text { Self-efficacy } \\
\text { Social support }\end{array}$ \\
\hline 10 & Self-esteem and self-efficacy. & $\begin{array}{l}\text { Link to an article about increasing self-esteem, feel- } \\
\text { ings of self-worth and motivation. } \\
\text { Asked to comment on activities done with friends } \\
\text { and/or family. Emailed a weekly workout log and } \\
\text { encouraged to stick to a program. }\end{array}$ & $\begin{array}{l}\text { Self-efficacy } \\
\text { Social support } \\
\text { Physical } \\
\text { Self-perception }\end{array}$ \\
\hline 11 & $\begin{array}{l}\text { Alternative activities_-Outdoor recreational } \\
\text { pursuits. }\end{array}$ & $\begin{array}{l}\text { Progress update-Write on wall. } \\
\text { Encouragement to increase physical activity. } \\
\text { Link to girls' outdoor education site for ideas to be } \\
\text { active. }\end{array}$ & $\begin{array}{l}\text { Self-efficacy } \\
\text { Social support }\end{array}$ \\
\hline 12 & $\begin{array}{l}\text { Completion of the program. } \\
\text { Encouragement to continue to increase phys- } \\
\text { ical activity behaviour and develop healthy } \\
\text { habits. }\end{array}$ & $\begin{array}{l}\text { Encouraged to continue to exercise in many different } \\
\text { ways and to engage in physical activity every day. } \\
\text { Link to government health sites for current and future } \\
\text { use. }\end{array}$ & $\begin{array}{l}\text { Self-efficacy } \\
\text { Social support }\end{array}$ \\
\hline
\end{tabular}

Note: Pom Pom's were made by the girls to use during baseline assessment in groups. Gymstick is an elasticized resistance bar that is attached to the feet. The "wall" is an area in Facebook used for a brief comment that is clearly seen. Discussion section is a larger area to write a more extensive discussion.

used to determine whether the girls were in the healthy weight, overweight or obese weight range (Cole, Bellizzi, Flegal, \& Dietz, 2000). The Queens College Step test (QCST) was used to provide an estimate of maximal oxygen uptake $\left(\mathrm{VO}_{2} \mathrm{max}\right)(\mathrm{Lu}-$ bans, Morgan, Callister, \& Collins, 2008). The girls stepped up and down for three minutes continuously using a $41 \mathrm{~cm}$ bench; wearing a Polar ${ }^{\odot}$ heart rate monitor at a cadence of 88 beats per minute set by a metronome. After three minutes the girls' heart rate was taken three times for 15 seconds at the time of 5 seconds, 10 seconds and 20 seconds after completion of the 3 minutes stepping (Zwiren, Freedson, Warn, Wilke, \& Rippe, 1991). The average of the three scores was calculated to estimate the maximal oxygen uptake $\left[\mathrm{VO}_{2} \mathrm{max}(\mathrm{ml} / \mathrm{kg} / \mathrm{min})=65.81-0.1847\right.$ $\times$ heart rate (beats/min)] (McArdle, Katch, Pchar, Jacobson, \& 
Ruck, 1972). Validated questionnaires were administered to measure self-efficacy scales (Motl et al., 2000) and peer social support scales (Prochaska, Redgers, \& Sallis, 2002), as these were identified as potential mediators of behavior (Lubans et al., 2008; Whitehead, Biddle, Donovan, \& Nevill, 2006).

The mixed-methods process evaluation used both questionnaires and focus groups to reveal insights into the recruitment, retention, adherence and program satisfaction among the intervention group. Upon completion of the intervention, the girls in the intervention group completed a process evaluation questionnaire and participated in a self-selected (based on friendship and time availability) focus group discussion for 30 minutes to reveal insights into their experiences and perceptions of GRASP-IT. The process evaluation was developed using the conceptual framework outlined by Crutzen that included items in the questionnaire being framed around three aspects of exposure 1) access to the intervention website; 2) staying long enough to use and process the information (noting that it is difficult to determine how long is enough) and 3) revisiting the intervention website (Crutzen et al., 2009). The questionnaire also included openended questions regarding satisfaction/enjoyment and suggestions for program improvement. The qualitative data for analysis of the process evaluation and focus groups responses were sorted into themed responses for the 12 process evaluation items and 12 focus group questions and responses grouped according to common responses and themes.

\section{Results}

\section{Analysis}

Comparisons of the intervention and control groups were completed using the Statistical Package for Social Sciences (SPSS) version 16 software and statistical significance was set at $p<0.05$. Data were assessed for normality and satisfied the criteria. Analysis of the covariance (ANCOVA) was used to evaluate the impact of the GRASP-IT intervention on primary and secondary outcomes. In the analysis the relationship between conditions (intervention and control) and time (baseline and follow-up) was examined. For each outcome, the follow-up score was the dependent variable, treatment condition was the fixed factor and the baseline score was the covariate. This analysis allowed for existing differences between groups at baseline to be controlled for in the analysis. Cohen's $d$ was used to determine effect sizes and was calculated using the mean difference ( 3 months minus baseline) between groups and the pooled standard deviation of change for the whole group. Effect sizes were interpreted as small $(d=0.20)$, medium $(d=0.50)$ or large $(d=0.80)$ (Cohen, 1988).

\section{Baseline Characteristics}

The flowchart for the study is displayed in Figure $\mathbf{1}$ and the baseline results are displayed in Table 2. All 52 girls recruited for the study were born in Australia and one was of Aboriginal descent. The average age of the girls was $15.7 \pm 1.5$ years. Physical activity for the intervention group was an average of 2639 steps less than the control group at baseline and the BMI result for the intervention group was similar to the control group being only $0.1 \mathrm{~kg} / \mathrm{m}^{2}$ difference between the means at baseline, additionally, the BMI $z$ scores are all low and indicate normal distribution (Table 2).

\section{Effect of Intervention on Primary Outcome}

The preliminary results for this study showed that there was no treatment effect for physical activity. However, an increase in physical activity from baseline to follow-up for the intervention group was found while physical activity for the control group regressed from baseline to follow-up (Table 3) and this represented a large effect size $(d=0.8)$.

\section{Effect of Intervention on Secondary Outcomes}

The effect of the intervention on secondary outcomes show a non significant reduction in BMI was observed among participants in the intervention group, with no change in BMI among those in the control group. At baseline, 73 per cent of participants were in the healthy weight for age range and this increased

Table 2.

Baseline values by group for outcomes.

\begin{tabular}{|c|c|c|c|c|c|c|}
\hline \multirow[t]{2}{*}{ Outcomes } & \multicolumn{2}{|c|}{$\begin{array}{l}\text { Control } \\
(\mathrm{n}=14)\end{array}$} & \multicolumn{2}{|c|}{$\begin{array}{l}\text { Intervention } \\
\quad(\mathrm{n}=21)\end{array}$} & \multicolumn{2}{|c|}{$\begin{array}{c}\begin{array}{c}\text { Whole } \\
(n=35)\end{array}\end{array}$} \\
\hline & Mean & SD & Mean & SD & Mean & SD \\
\hline Age & 15.6 & 0.5 & 15.7 & 0.5 & 15.7 & 0.5 \\
\hline Weight & 59.8 & 8.8 & 61.9 & 10.6 & 61.1 & 9.7 \\
\hline Height & 1.62 & 0.5 & 1.65 & 0.0 & 1.64 & 0.5 \\
\hline BMI & 22.8 & 3.7 & 22.7 & 4.1 & 22.8 & 3.9 \\
\hline BMI $z$ scores & -0.004 & -0.0 & 0.0 & 0.9 & -0.002 & 0.45 \\
\hline $\mathrm{VO}_{2} \max$ & 35.4 & 2.0 & 35.2 & 3.2 & 35.3 & 2.6 \\
\hline Mean steps/day ${ }^{\mathrm{a}}$ & 11,690 & 4696 & 9051 & 3466 & 10,370 & 4081 \\
\hline Self-efficacy ${ }^{\mathrm{b}}$ & 3.7 & 0.7 & 3.4 & 0.5 & 3.6 & 0.6 \\
\hline Peer support ${ }^{\mathrm{b}}$ & 2.3 & 0.9 & 1.9 & 0.9 & 2.1 & 0.9 \\
\hline
\end{tabular}

${ }^{\mathrm{a}}$ Students wore pedometers for 4 weekdays and 1 weekend day; ${ }^{\mathrm{b}}$ Questionnaire scales range from 0 to 4 .

Table 3.

GRASP-IT intervention effects at post-intervention.

\begin{tabular}{|c|c|c|c|c|c|c|}
\hline \multirow{2}{*}{ Outcomes } & \multirow{2}{*}{$\begin{array}{c}\text { Assess- } \\
\text { ment }\end{array}$} & \multicolumn{2}{|c|}{ Mean (SD) } & \multicolumn{3}{|c|}{ Group $\times$ Time } \\
\hline & & Control & Intervention & $\mathrm{F}$ & $\mathrm{P}$ & $\mathrm{D}$ \\
\hline Weight (kg) & $\begin{array}{l}\text { Baseline } \\
\text { post }\end{array}$ & $\begin{array}{l}59.8(8.8) \\
60.0(8.6)\end{array}$ & $\begin{array}{c}61.9(10.6) \\
60.3(8.9)\end{array}$ & 1.46 & 0.235 & -0.1 \\
\hline Height (cm) & $\begin{array}{l}\text { Baseline } \\
\text { post }\end{array}$ & $\begin{array}{l}1.62(0.5) \\
1.63(0.6)\end{array}$ & $\begin{array}{l}1.65(0.0) \\
1.66(0.1)\end{array}$ & 1.01 & 0.321 & 0.0 \\
\hline BMI $\left(\mathrm{kg} / \mathrm{m}^{2}\right)$ & $\begin{array}{l}\text { Baseline } \\
\text { post }\end{array}$ & $\begin{array}{l}22.8(3.7) \\
22.8(3.8)\end{array}$ & $\begin{array}{l}22.7(4.1) \\
21.8(3.2)\end{array}$ & 2.48 & 0.124 & -0.5 \\
\hline BMI $z$ score & $\begin{array}{l}\text { Baseline } \\
\text { post }\end{array}$ & $\begin{array}{l}0.0(0.9) \\
0.2(1.1)\end{array}$ & $\begin{array}{l}-0.0038(-0.0) \\
-0.1068(-0.1)\end{array}$ & 2.48 & 0.124 & -0.6 \\
\hline $\begin{array}{c}\mathrm{VO}_{2} \max \\
(\mathrm{ml} / \mathrm{kg} / \mathrm{min})\end{array}$ & $\begin{array}{l}\text { Baseline } \\
\text { post }\end{array}$ & $\begin{array}{l}35.4(2.0) \\
36.3(2.1)\end{array}$ & $\begin{array}{l}35.2(3.2) \\
35.6(2.4)\end{array}$ & 0.00 & 0.967 & 0.1 \\
\hline Steps per day ${ }^{\mathrm{a}}$ & $\begin{array}{l}\text { Baseline } \\
\text { post }\end{array}$ & $\begin{array}{c}11,690(4696) \\
9812(4745)\end{array}$ & $\begin{array}{l}9051(3466) \\
9883(3512)\end{array}$ & 2.75 & 0.112 & 0.8 \\
\hline Self-efficacy ${ }^{b}$ & $\begin{array}{l}\text { Baseline } \\
\text { post }\end{array}$ & $\begin{array}{l}3.7(0.7) \\
3.6(0.8)\end{array}$ & $\begin{array}{l}3.4(0.5) \\
3.5(0.7)\end{array}$ & 3.72 & 0.06 & 0.8 \\
\hline Peer support ${ }^{\mathrm{b}}$ & $\begin{array}{l}\text { Baseline } \\
\text { post }\end{array}$ & $\begin{array}{l}2.3(0.9) \\
2.2(1.0)\end{array}$ & $\begin{array}{l}1.9(0.9) \\
2.1(0.9)\end{array}$ & 2.12 & 0.16 & 0.6 \\
\hline
\end{tabular}

Note: The means and standard deviation (SD) are reported for all participants BMI = Body Mass Index; Effect sizes $(d)$ were calculated by subtracting baseline from post-test values then dividing by the pooled standard deviation of change. ANCOVA was used to compare the means between treatment and control condi-

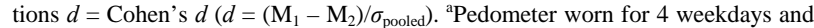
1 weekend day; ${ }^{\text {b }}$ uestionnaire scales range from 0 to 4 . 
to 92 per cent at follow up. In addition, those in the overweight category decreased from 19 per cent to 4 per cent and those in the obese category decreased from 8 per cent to 4 per cent respectively (Cole et al., 2000). Large effect sizes were noted for self-efficacy $(d=0.8)$. The estimated $\mathrm{VO}_{2}$ max of girls in both intervention and control groups increased slightly but with no significant difference between groups (Table 3). Self-efficacy and social support marginally increased $(p=0.06)$ between groups and improved slightly for the intervention group.

\section{Process Evaluation}

Recruitment at both schools was generally successful with 29 girls recruited at the intervention school and 23 girls at the control school. Retention and adherence to the assessment components of the program was low and the drop off rate of the girls to log and/or return their pedometers decreased during the 12week time-frame (Figure 1) The intervention retention for the face-to-face component was high (mean $80 \%$ attendance) for the six week time-frame. However, the number of girls who registered and participated during the on-line component of the intervention was low (33 percent registered). The intervention school process evaluation $(n=24)$ revealed that the girls were satisfied with the GRASP-IT study. However, they indicated that they preferred a face-to-face program rather than an internet- led program. Of note was there preferred atmosphere to engage in physical activity being with a small group of friends (Table 4).

Focus groups revealed that the girls would prefer to interact with friends online using Myspace not Facebook. During the focus group sessions the girls indicated that they were not interested in the online activities and therefore, would not have stayed on the site long enough to benefit from its use. The three main themes extracted from the focus group responses were firstly, the girl's lack of interest to register and engage with each other using the Facebook site. Quotes regarding the online component stated "Facebook is for old people" and "Facebook is for the older generation". Secondly, they indicated a preference for MySpace over Facebook to interact online stating "MySpace is for the younger generation" and "we all know how to use MySpace and we enjoy it more". The third theme was a preference for the program to be extended with many girls stating "I think it should be longer and we want more time".

\section{Discussion}

The aim of this study was to report the feasibility and preliminary efficacy of GRASP-IT intervention which utilized both face-to face and online components. Notably, this is the first study to evaluate a program that utilized a social networking

Table 4.

Process evaluation for the GRASP-IT study.

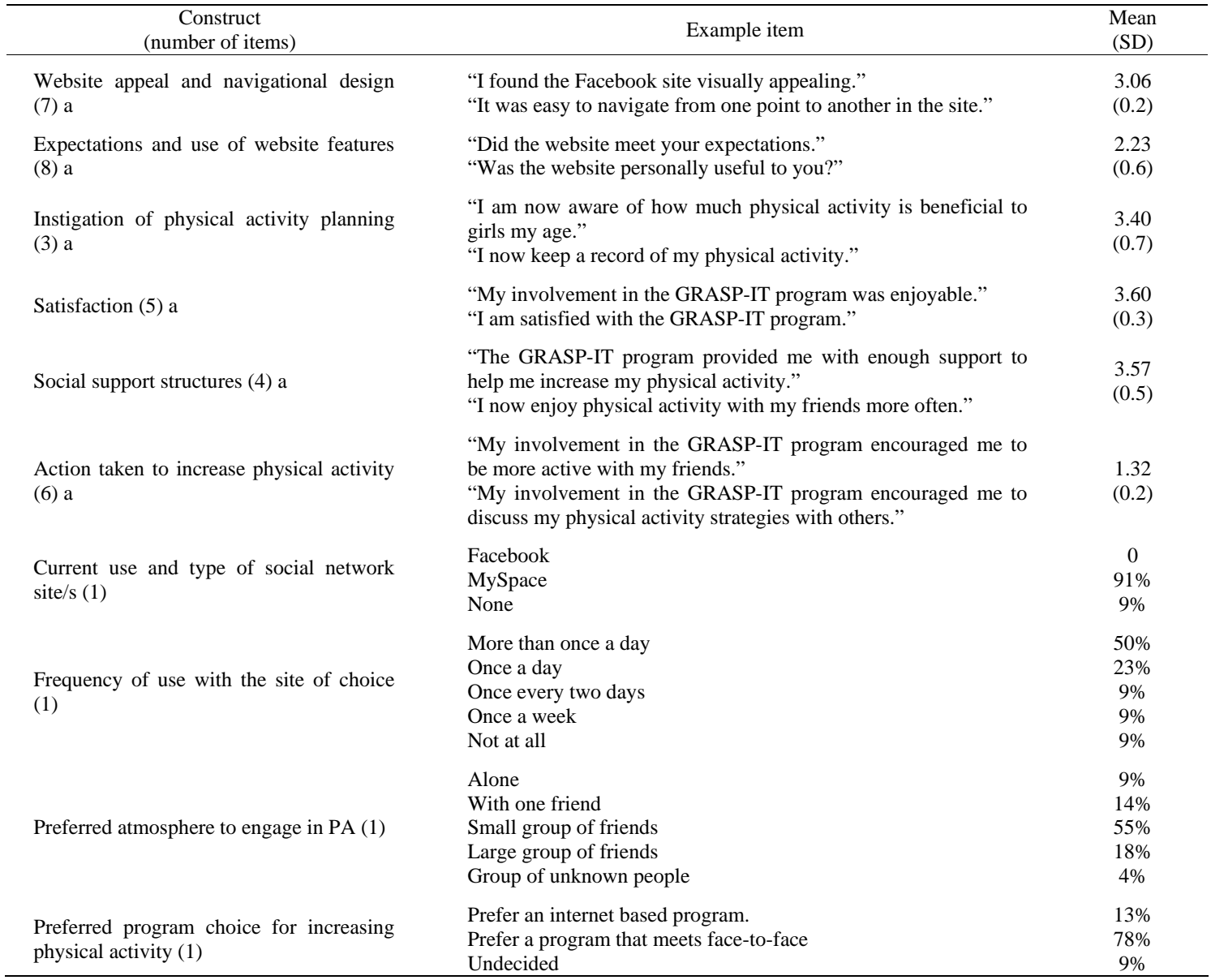

Note: a = item measured on a scale of 1 to 5 . 
component to increase physical activity in adolescent girls. Although participants in the GRASP-IT intervention group increased their physical activity and enjoyed the face-to-face intervention component, engagement and compliance with the online component was low. Our failure to detect a statistically significant between group differences for physical activity was likely due to our sample size and inadequate statistical power as a pilot study. It was encouraging to note that self-efficacy and peer support all improved during the 12-week study among participants in the intervention group. However, there was no between group differences and the sample size may have also been a possible explanation and limitation to our study. The use of the internet to promote physical activity is an emerging area of research and no previous study has attempted to engage adolescent girls using social networking sites (Buis et al., 2009). Many factors may have potentially hindered the success of the program, and in particular, use of the social network site Facebook for social support to be active. First, in the majority of Australian schools social networking sites used by adolescents are currently blocked by the educational authorities in state system schools and students cannot access them during the school day while at school (Department of Education and Training, 2010). Second, limited ongoing support for the online component of GRASP-IT existed as there was minimal contact with the researcher for phase two. During phase one an outline was given about the online component at the initial information session, a further session to guide and encourage online Registration and use at the end of the face-to-face session was delivered and then reminders sent to the girls via email during phase two was conducted. Furthermore, we found that girls preferred mode of delivery for increasing physical activity was one that meets face-to-face (78 percent) over an internet based (13 percent) program.

A limited number of previous intervention studies have exclusively targeted older adolescent girls' physical activity (Dishman et al., 2005; Eliakim et al., 1996; Jamner et al. 2004; Murphy, Ni Khuinn, Browne, \& O’Rathaille, 2006; NeumarkSztainer, Story, Hannan, \& Rex, 2003; Schneider, Dunton, \& Cooper, 2008), but none have combined face-to-face component with the use of a social networking site to enhance social support for physical activity. While many previous studies have successfully increased their physical activity in this cohort, they have all differed in their design and delivery. One study, Project $\mathrm{FAB}$, did use the internet for participants to record physical activity but not to support or motivate girls to increase physical activity (Schneider et al., 2007). Another study promoted a selfled activity program versus a teacher-led activity program and concluded that both groups significantly increased physical activity however, the self-led program group also continued physical activity after the intervention (Murphy et al., 2006) which demonstrates the need for studies to follow-up participants after an intervention has concluded. The length of physical activity interventions is also a key influencing factor in promoting selfefficacy and ramifications of a longer GRASP-IT study with a more comprehensive face-to-face component may have been required to further increase self-efficacy. Of note, Project FAB researchers described that a program that is longer than two semesters, or 6 months or more, is more likely to successfully impact on physical activity, as physical activity increased in the later months of their intervention as did New Moves intervention (Neumark-Sztainer et al., 2003; Schneider et al., 2007).

Our process evaluation provided a number of insights re- garding elements of the GRASP-IT intervention. In general, the girls were satisfied with the GRASP-IT intervention and were more likely to self-monitor their physical activity at posttreatment. They believed the GRASP-IT intervention provided them with enough support to be active but interestingly, they believed that this level of support did not necessarily lead to physical activity behaviour change. Despite the girls preference for participating in physical activity in small groups of friends, rather than alone or in a large group, additional strategies may be required to encourage girls to provide social support for physical activity for each other. We determined that they preferred a longer program however, we were not able to determine whether they would have liked more face-to-face sessions and/or an extended period of time to engage with the website, however, future studies should consider integrating both the face-to-face and online component to encourage compliance, monitor use and trouble shoot to maximize the intervention dose and potentially impact on physical activity behaviour. That is, engagement with the website may have been greater if the face-to-face component used some time to encourage, clarify and motivate the girls to use the website in conjunction with the face-to-face activities. GRASP-IT recruitment at both schools was initially successful; however, strategies to address compliance for the collection of physical activity data is an issue to be further addressed in future studies (NeumarkSztainer et al., 2003; Schneider et al., 2007).

\section{Conclusion}

This is the first study that has attempted to engage older adolescent girls to increase their physical activity behaviour using the social networking site Facebook. We recommend that future programs targeting older adolescent girls could include an increase in the length of time for face-to-face sessions to maximize outcomes given the girls preference for this medium and the possible investigation of other more popular sites that may be more desirable for adolescent girls to engage and enjoy while supporting each other to be physically active. The internet is clearly an emerging area for engaging the youth of today with a high use of technology on their agenda for social, educational and entertainment pursuits. Interventions need to embrace this technologically evolving world and consider innovative ways to engage older adolescent girls in physical activity. The availability of computer access with internet is increasing and advancing technology in schools will give many adolescent girls access to internet support, both during schools hours and out of school hours and this in turn may potentially benefit their health through the use of programs such as GRASP-IT.

\section{REFERENCES}

ACM SIGCOMM Conference (2008). Unveiling Facebook: A measurement study of social network based applications. URL (last checked 25 October 2011).

http://dl.acm.org/citation.cfm?id=1452527

Bandura, A. (1986). Social foundations of thought and action: A social cognitive theory. Englewood Cliffs, NJ: Prentice-Hall.

Biddle, S., Gorley, T., \& Stensel, D. (2004). Health-enhancing physical activity and sedentary behavior in children and adolescents. Journal of Sports Sciences, 22, 679-701. doi:10.1080/02640410410001712412

Biddle, S, \& Wang, C. (2003). Motivation and self-perception profiles and links with physical activity in adolescent girls. Journal of Adolescence, 26, 687-701. doi:10.1016/j.adolescence.2003.07.003 
Booth, M., Okely, A., Denny-Wilson, E., Hardy, L., Yang, B., \& Dobbins, T. (2006). NSW schools physical activity and nutrition survey (SPANS) 2004: Full Report, Sydney.

Buis, L., Poulton, T., Holleman, R., Sen, A., Resnick, P., Goodrich, D. E. et al. (2009). Evaluating Active U: An internet-mediated physical activity program. BioMedical Central Public Health, 9.

Cohen, J. (1988). Statistical power analysis for the behavioural sciences. Hillsdale, NJ: Earlbaum Associates.

Cole, T. J., Bellizzi, M. C., Flegal, K. M., \& Dietz, W. H. (2000). Establishing a standard definition for child overweight and obesity worldwide: International survey. Brittish Medical Journal, 320, 1240-1243. doi:10.1136/bmj.320.7244.1240

Crutzen, R., De Nooijer, J., Brouwer, W., Oenema, A., Brug, J., \& DeVries, N. K. (2009). A conceptual framework for understanding and improving adolescents' exposure to internet-delivered interventions. Health Promotion International, 24, 277-283. doi:10.1093/heapro/dap018

Department of Health and Ageing (2004). National physical activity guidelines for Australia. Canberra.

Department of Health and Ageing (2008). 2007 Australian national children's nutrition and physical activity survey: Main findings. Canberra.

Dishman, R. K., Motl, R. W., Sallis, J. F., Dunn, A. L., Birnbaum, A. S., Welk, G. J. et al. (2005). Self-management strategies mediate selfefficacy and physical activity. American Journal of Preventive Medicine, 29, 10-18. doi:10.1016/j.amepre.2005.03.012

Dishman, R. K., Motl, R. W., Saunders, R., Felton, G., Ward, D. S., Dowda, M. et al. (2004). Self-efficacy partially mediates the effect of a school-based physical-activity intervention among adolescent girls. Preventive Medicine, 38, 628-636. doi:10.1016/j.ypmed.2003.12.007

Eliakim, A., Barstow, T. J., Brasel, J. A., Ajie, H., Lee, W. N. P., Renslo, R. et al. (1996). Effect of exercise training on energy expenditure, muscle volume, and maximal oxygen uptake in female adolescents. The Journal of Pediatrics, 129, 537-543. doi:10.1016/S0022-3476(96)70118-X

Jamner, M. S., Spruijt-Metz, D., Bassin, S., \& Cooper, D. M. (2004). A controlled evaluation of a school-based intervention to promote physical activity among sedentary adolescent females: Project FAB. Journal of Adolescent Health, 34, 279-289.

Kazeniac, A. (2010). Social networks: Facebook takes over top spot, twitter climbs. URL (last checked 25 October 2011).

http://blog.compete.com/2009/02/09facebook-myspace-twitter-socialnetwork/

Lubans, D. R., Foster, C., \& Biddle, S. J. H. (2008). A review of mediators of behavior in interventions to promote physical activity among children and adolescents. Journal of Preventative Medicine, 47, 463-470. doi:10.1016/j.ypmed.2008.07.011

Lubans, D. R., Morgan, P. J., Callister, R., \& Collins, C. E. (2008). The relationship between pedometer step counts and estimated $\mathrm{VO}_{2}$ max as determined by submaximal fitness test in adolescents. Pediatric Exercise Science, 20, 273-284.

Lubans, D. R., Morgan, P. J., \& Tudor-Locke, C. (2009). A systematic review of studies using pedometers to promote physical activity among youth. Preventative Medicine, 48, 307-315. doi:10.1016/j.ypmed.2009.02.014

McArdle, W. D., Katch, F. I., Pchar, G. S., Jacobson, L., \& Ruck, S. (1972). Reliability and interrelationships between the maximal oxygen uptake, physical work capacity, and step test scores in college women. Medicine \& Science in Sports \& Exercise, 4, 182-186. doi:10.1249/00005768-197200440-00019

Motl, R. W., Dishman, R. K., Trost, S. G., Saunders, R. P., Dowda, M., \& Felton, G. (2000). Factorial validity and invariance of questionnaires measuring social-cognitive determinants of physical activity among adolescent girls. Preventative Medicine, 31, 584-594. doi:10.1006/pmed.2000.0735

Murphy, N. M., Ni Dhuinn, M., Browne, P. A., \& ÓRathaille, M. M. (2006). Physical activity for bone health in inactive teenage girls: Is a supervised, teacher-led program or self-led program best? Journal of
Adolescent Health, 39, 508-514.

doi:10.1016/j.jadohealth.2006.01.008

Nader, P., Bradley, R., Houts, R., Ritchie, S., \& O’Brien, M. (2008). Moderate-to-vigorous physical activity from ages 9 to 15 years. Journal of American Medical Association, 300, 295-305. doi:10.1001/jama.300.3.295

Neumark-Sztainer, D., Story, M., Hannan, P. J., \& Rex, J. (2003). New moves: A school-based obesity prevention program for adolescent girls. Preventive Medicine, 37, 41-51. doi:10.1016/S0091-7435(03)00057-4

New South Wales Government Board of Studies (2010). Complete NSW board of studies statistics archive. URL (last checked 25 October 2011). http://www.boardofstudies.nsw.edu.au

Norman, G. J., Zabinski, M. F., Adams, M. A., Rosenberg, D. E., Yaroch, A. L., \& Atienza, A. A. (2007). A review of ehealth interventions for physical activity and dietary behavior change. American Journal of Preventive Medicine, 33, 336-345. doi:10.1016/j.amepre.2007.05.007

New South Wales Department of Education and Communities (2010). Digital education revolution NSW. URL (last checked 25 October 2011). https://www.det.nsw.edu.au/strat_direction/schools/dernsw/index

Pate, R., Dowda, M., O’Neill, J., \& Ward, D. (2007). Change in physical activity participation among adolescent girls from 8th to 12th grade. Journal of Physical Activity \& Health, 4, 3-16.

President's Council on Physical Fitness and Sports (2002). The presidential Active Lifestyle Award (PALA). Washington: US Department of Health and Human Services.

Prochaska, J. J., Rodgers, M. W., \& Sallis, J. F. (2002). Association of parent and peer support with adolescent physical activity. Research Quarterly for Exercise and Sport, 73, 206-210.

Schneider, M., Dunton, G. F., Bassin, S., Graham, D. J., Eliakim, A., \& Cooper, D. M. (2007). Impact of a school-based physical activity intervention on fitness and bone in adolescent females. Journal of Physical Activity and Health, 4, 17-29.

Schneider, M., Dunton, G. F., \& Cooper, D. M. (2008). Physical activity and physical self-concept among sedentary adolescent females: An intervention study. Psychology of Sport \& Exercise, 9, 1-14. doi:10.1016/j.psychsport.2007.01.003

Schofield, G., Schofield, L., Hinckson, E. A., \& Mummer, W. K. (2007). Daily step counts and selected coronary heart disease risk factors in adolescent girls. Journal of Science and Medicine in Sport, 12, 148-155. doi:10.1016/j.jsams.2007.10.003

Stevens, J., Murray, D. M., Catellier, D. J., Hannan, P. J., Lytle, L. A., Elder, J. P. et al. (2005). Design of the Trial of Activity in Adolescent Girls (TAAG). Contemporary Clinical Trials, 26, 223-233. doi:10.1016/j.cct.2004.12.011

Thelwall, M. (2008). Social networks, gender and friending: An analysis of MySpace member profiles. Journal of American Society for Information Science and Technology, 59, 1320-1330. doi:10.1002/asi.20835

Tudor-Locke, C., \& Bassett, D. R. Jr. (2004). How many steps/days are enough: Preliminary pedometer indices for public health. Sports Medicine, 34, 1-8. doi:10.2165/00007256-200434010-00001

US Department of Health and Human Services (2000). Healthy people 2010: Understanding and improving health. Washington DC: USA Government Printing Office.

Van Sluijs, E. M., McMinn, A. M., \& Griffin, S. J. (2007). Effectiveness of interventions to promote physical activity in children and adolescents: Systematic review of controlled trials. British Medical Journal, 335.

Whitehead, S. H., Biddle, S. J. H., O’Donovan, T. M., \& Nevill, M. E. (2006). Social-psychological and physical environmental factors in groups differing by levels of physical activity: A study of Scottish adolescent girls. Pediatric Exercise Science, 18, 226-239.

WHO (2004). Global strategy on diet, physical activity and health. World Health Organization.

Zwiren, L. D., Freedson, P. S., Ward, A., Wilke, S., \& Rippe, J. M. (1991). Estimation of $\mathrm{VO}_{2}$ max: A comparative analysis of five exercise tests. Research Quarterly for Exercise \& Sport, 62, 73-78. 